\title{
Scar endometriosis: Does the medical treatment with LHRH analogue have an effect on its symptomatology and lesions sizes?
}

\author{
Original \\ Article \\ Mahmoud Thabet', Hamed Youssef', Ahmed Abd El Khalek ${ }^{2}$ \\ ${ }^{I}$ Department of Obstetrics \& Gynecology, Faculty of Medicine, Mansoura University, Egypt \\ ${ }^{2}$ Department of Diagnostic Radiology, Faculty of Medicine, Mansoura University, Egypt
}

\begin{abstract}
Background: Endometriosis defined as the presence of endometrial glands and stroma like tissues outside the uterine cavity. Scar endometriosis (SE) is a rare entity that is difficult to reach diagnosis due to the absence of a uniform clinical presentation with a variety in symptomatology and signs. It is usually a conflict for physicians of different specialists (surgeon, dermatologist, obstetrician, and gynecologist) that delay diagnosis.

Objective Studying the effect of medical treatment with luteinizing hormone-releasing hormone (LHRH) analogue on pain and mass size as a short-term therapy for cases with scar endometriosis that help postponing and reducing dissection size of the surgical intervention.

Patients and Methods: Our study included 14 patients, aged 18 to $40 \mathrm{y}$, having a previous gynecological or obstetric operation, a painful scar that may increase with menstruation, tender scar and mass palpable under scar diagnosed as scar endometriosis seen in our Mansoura University Hospital (MUH) and Private Clinic over 4.5 years. All patients underwent the following steps to reach a diagnosis ; history taking, examination and lab investigation, operative details and pain (visual analog scale). VAS scores pre-treatment were recorded then patients referred to ultrasound evaluation where any patients with suspicion of scar endometrioma underwent confirmation with FNAC (fine needle aspiration cytology). Patients diagnosed as scar endometriomas received LHRH analogue (Zoladex 3.6mg/month) for 6 months, then VAS score and ultrasound mass size were performed monthly and at the end of the medical treatment period. Patients who had no pain relief at the end of the treatment period were prepared for wide surgical excision with safety margins. Evaluation of the effect of short-term medical treatment as the post-treatment pain VAS score and mass size in comparison to their pretreatment findings were recorded in addition to its effect on surgical intervention postpone.

Results: The study of the 14 patients showed that mean \pm SD of age was $28.79 \pm 4.99$, mean \pm SD of BMI was $26.4 \pm 1.7$, previous operation scar (Umbilical laparoscopic port 2 [14.3\%], episiotomy 3 [21.4\%] and cesarean scar (CS) scar 9[64.3\%]). Cystic mass was 8[57.1\%], heterogeneous mass was $6[42.9 \%]$ and mean \pm SD of US size/cm was $2.42 \pm 0.67$ (1.6-4.1). Median of pain duration/months was 26.0 (5.0-60.0). Mean \pm SD of pain VAS score before treatment was 8.0 (6.0-10.0), while after was $2.0(0-8.0)$. Median of pain VAS score in cases with cystic lesions before and after treatment was 7.5 (6.0-9.0) and 1.0(0.0-7.0), respectively, with a statistically significant difference. Also, median of pain VAS score in cases with heterogeneous lesions before and after treatment was 9.0 (7.0-10.0) and $7.0(2.0-8.0)$, respectively, with a statistically significant difference with more pain relieve in cystic cases than heterogenous one. Patients needed for surgical intervention and not responding to medical treatment were 8 [57.1\%]. The cut of the level of US size of cystic lesions was $\leq 2.65 \mathrm{~cm}$, while for heterogeneous lesions was $\leq 2.20 \mathrm{~cm}$ with an accuracy of $87.5 \%$ and $83.3 \%$, respectively.

Conclusion: LHRH analogue short-term treatment for scar endometriosis is significantly effective in pain to relieve and decrease mass size in cystic lesions $\leq 2.65 \mathrm{~cm}$ and heterogeneous lesions $\leq 2.05 \mathrm{~cm}$ that allow surgical intervention postpone and minimize surgical dissection site.
\end{abstract}

Key Words: LHRH analogue, scar endometriosis, surgical intervention,VAS score

Received: $16^{\text {th }}$ August 2019, Accepted: $14^{\text {th }}$ September 2019

Corresponding Author: Mahmoud Thabet, Department of Obstetrics \& Gynecology, Faculty of Medicine, Mansoura University, Tel.: 01003398201, E-mail: thabet0777@gmail.com

ISSN: 2090-7625, November 2019, Vol.9, No. 4

\section{INTRODUCTION}

Extrapelvic endometriosis is a rare condition, which was defined as the presence of endometrial tissue outside the pelvis ${ }^{[1,2]}$. Scar endometriosis is an uncommon form of extrapelvic endometriosis that is usually misdiagnosed as a desmoid tumor, lipoma, sebaceous cyst, hematoma, abscess, suture granuloma, incisional hernia or tumors, causing 
difficulty in diagnosis. It mostly occurs in old surgical scars from obstetrical and gynecological procedures ${ }^{[2]}$. Scar endometriosis is a rare entity but is becoming more frequent nowadays after increasing the rate of cesarean section (Pfannenstiel syndrome) as demonstrated in a systematic review by Horton et al ${ }^{[3]}$ It was also reported in a trocar port following laparoscopic surgery with increasing in the number of laparoscopic procedures in gynecologic and general surgery procedures ${ }^{[4,5]}$. The cause of scar endometriosis is unknown till now and many theories have been postulated. However, one of the most accepted theory is the iatrogenic transplantation of endometrial tissue or placental cells into the wound edge during abdominal or pelvic surgery ${ }^{[6-9]}$. The presentation of scar endometriosis and surgical procedure interval vary from months to years (3 months-10 years) in many series ${ }^{[10]}$. Scar endometriosis manifestations are nonspecific and may be associated with abdominal pain increasing at time of menstruation $^{[1]}$, tender scar and/or a firm and palpable nodule ${ }^{[12]}$. It should be suspected when there is pain and swelling at an incisional site after gynecologic or obstetric surgery in the reproductive age of the lady ${ }^{[10]}$. Many non-invasive diagnostic imaging modalities like ultrasonography with color Doppler, CT scan and MRI that can give correct but nonspecific diagnosis ${ }^{[6,13]}$. The accuracy of FNAC from the mass documented in many studies as an important confirmatory investigation ${ }^{[14,15]}$. The definitive diagnosis is made through a biopsy or through a fine needle aspiration biopsy (FNA) showing the usual morphological features of endometriosis ${ }^{[16,17]}$. Therapeutic management is essentially based on large surgical excision, with safety margins and damaged tissue fascial defect reconstruction that may need closure with synthetic mesh. Medical treatment including hormone suppression has been suggested to relieve clinical symptoms ${ }^{[18]}$.

\section{PATIENTS AND METHODS}

This is a prospective cohort study that was conducted in the antenatal clinic, Mansoura University Hospital Antenatal Department and Private Clinic over 4.5 years. The study was approved by the local Institutional Research Ethical Committee (institutional research board). Our study was carried out on 14 patients aged (18 to $40 \mathrm{y}$ ) having a previous gynecological or obstetric operation, painful scar that might increase with menstruation, tender scar, mass palpable under scar (Fig. 1) and did not complain of pelvic endometriosis symptomatology or history of pelvic endometriosis and diagnosed as scar endometriosis. All patients underwent the following steps to reach diagnosis, history taking, examination and lab investigation, operative details and pain VAS scores pre-treatment were recorded then patients referred to ultrasonography with color Doppler evaluation where scar mass were evaluated (Figs. 2 and 3) and any patients with suspicion of scar endometrioma (nonhomogeneous hypoechoic texture with scattered internal hyperechoic echoes in addition to irregular spiculated margins, that infiltrating the adjacent tissues with a variable size hyperechoic ring and an avascular single pedicle entering the mass at the periphery with color Doppler) ${ }^{[6,13]}$ were undergone confirmation with FNAC (fine needle aspiration cytology) using $10 \mathrm{ml}$ syringe and a 25-gauge needle where air-dried direct smears were stained with Papanicolaou stained following alcohol fixation (endometriosis identification with FNA is based on the presence of at least two of three findingsendometrial glandular cells, spindle endometrial stromal cells, and hemosiderin-laden macrophages $)^{[19]}$. Patients diagnosed as scar endometriomas had received LHRH analogue (zoldex $3.6 \mathrm{mg}$ ) monthly for 6 months, then pain VAS score and ultrasound mass size were performed monthly and at the end of medical treatment period and patients who did have pain relief at the end of the treatment period were prepared for wide surgical resection with safety margin (Fig. 4) and the specimens were referred for histopathological confirmation. Evaluating the effect of short-term medical treatment as the post-treatment pain VAS score and mass size in comparison to their pretreatment findings were recorded in addition to its effect on surgical intervention postpone. Written consent was given for all participants before being included and after explaining the study with the patient's ability to be withdrawn at any time under her own will.

\section{STATISTICAL ANALYSIS:}

Data were fed to the computer and analyzed using IBM SPSS software package version 22.0. Qualitative data were described using number and percent. Quantitative data were described using range (minimum and maximum), mean, standard deviation and median. The significance of the obtained results was judged at the 5\% level. Mann Whitney $U$ test and Wilcoxon signed rank test for comparison of parametric continuous variables comparing between groups and between before and after treatment. Spearman correlation was used to correlate continuous non-parametric variables. 


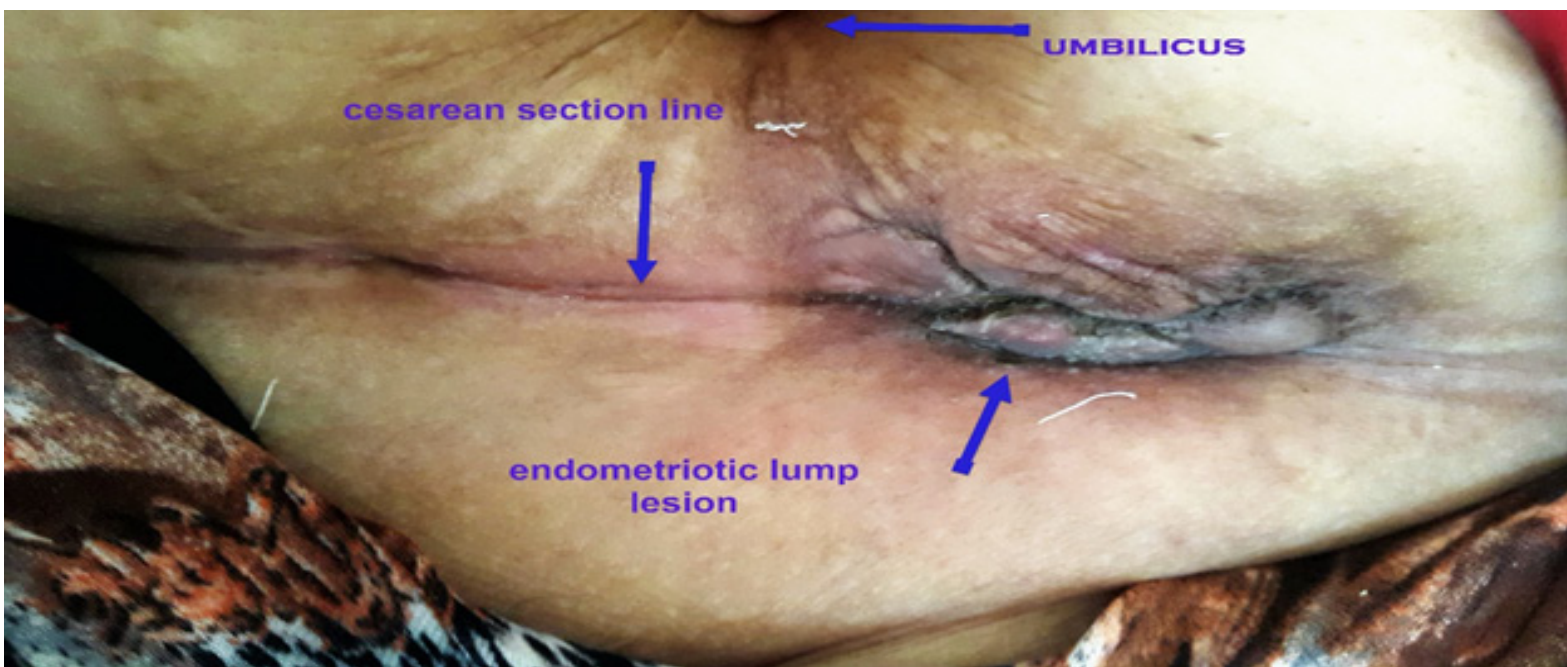

Fig. 1: Dark bluish mass involving the left side of the cesarean incision

\begin{abstract}
fairly defined oval shaped hypo-echoic lesion measures about $4 \times 2 \mathrm{~cm}$ is noticed involving the subcutaneous layer of the suprapubic region (involving the site of previous cesarean scar)with no surrounding edema or signs of increased vascularity seen inside (suspicious endometrioma)
\end{abstract}

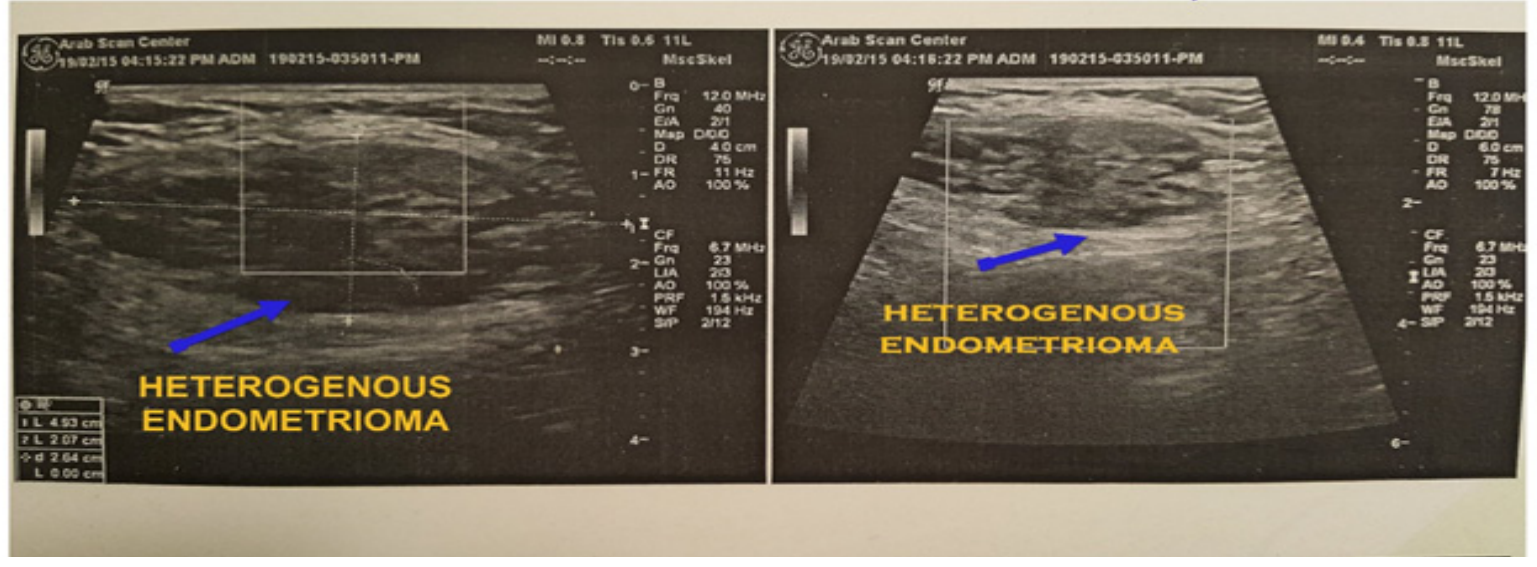

Fig. 2: Oval shaped heterogenous mass $4 \times 2 \mathrm{~cm}$ in subcutaneous layer at cesarean scar incision
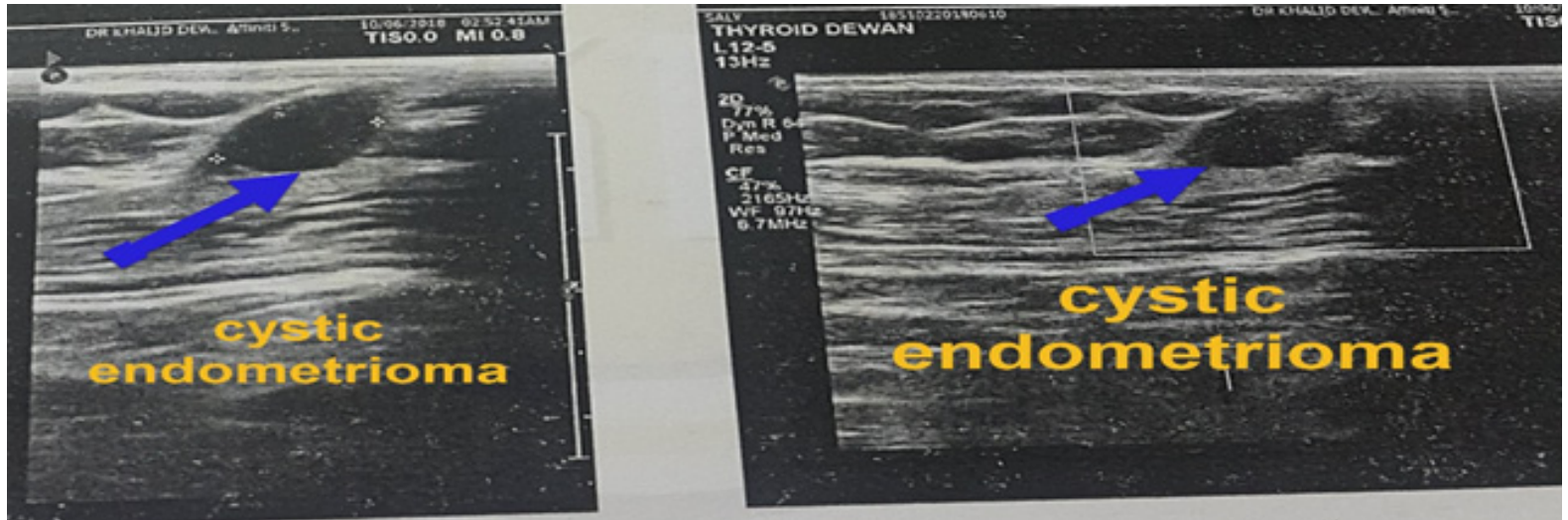

\title{
left suprapubic subcutaneous cystic mass $0.8 \times 0.6 \mathrm{~cm}$
}

Fig. 3: Left cystic lump under cesarean scar incision about $0.8 \times 0.6 \mathrm{~cm}$ 


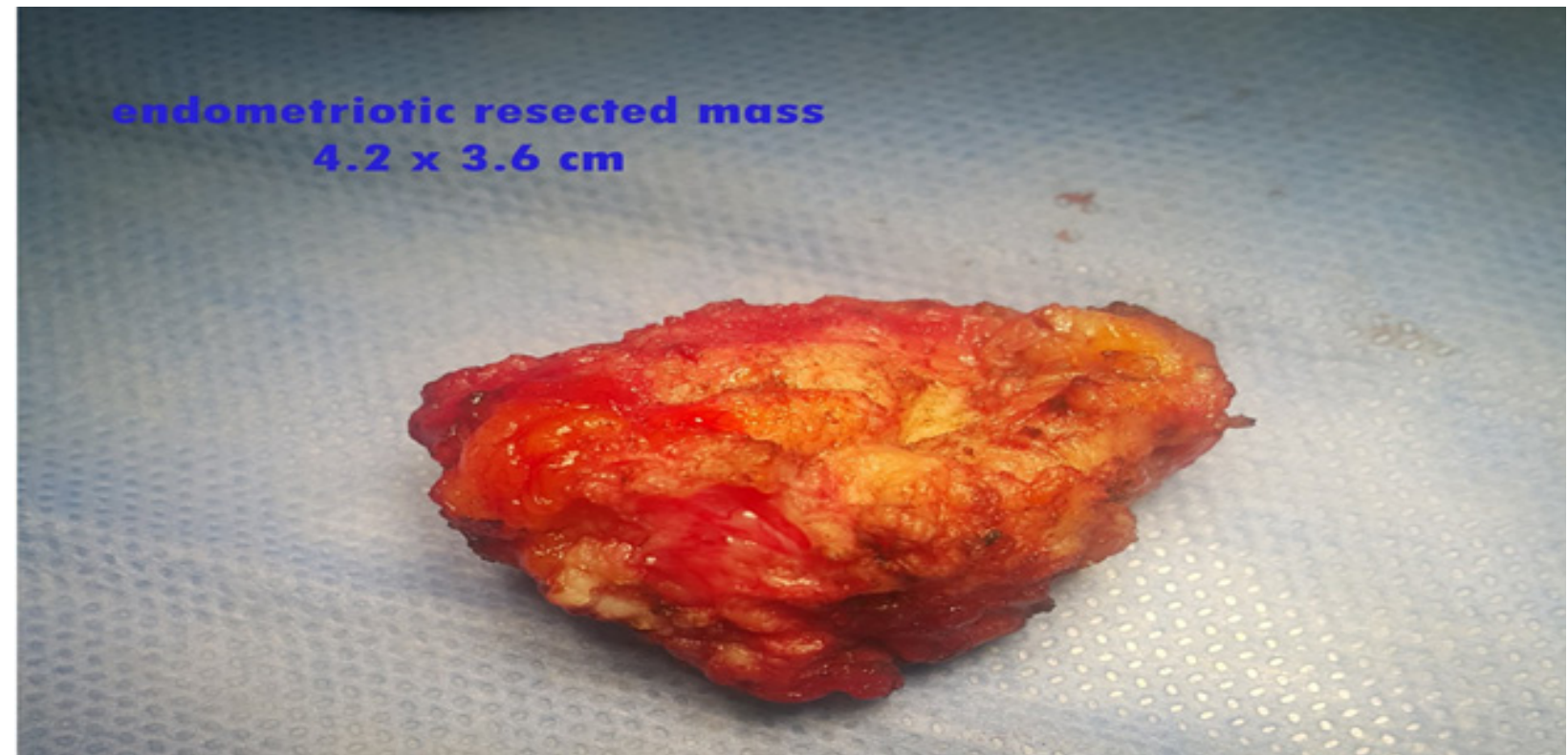

Fig. 4: Excised endometrioma from the subcutaneous tissue under cesarean section scar

\section{RESULTS}

The study was carried out on 14 patients diagnosed as scar endometriosis which revealed that patient's age mean was 28.79 (21-37), BMI mean was 26.4 (22.6-29.3), patients mostly multigravida and multipara with median was $2(0-4)$ and $2(0-3)$, respectively, previous operation scar (mostly had previous cesarean section (CS) scar 9[64.3\%], then episiotomy 3 [21.4\%] and lastly umbilical laparoscopic port $2[14.3 \%])$, US mass consistency criteria revealed that 8 cystic mass [57.1\%] and 6 heterogenous mass [42.9\%] as shown in diagram1, the mean of US size/cm was 2.42 (1.6-4.1), the mean of pain VAS score before medical treatment was $8.0(6.0-10.0)$ while after was $2.0(0-8.0)$ with a highly significant statistical difference between them, the pain duration median/ months was 26.0 (5.0-60.0) and patients needed for surgical intervention(wide local excision with safety margins) and not responding to medical treatment were $8[57.1 \%]$ while those respond to treatment (pain relief and decrease mass size) were $42.9 \%$ as shown in table 1 and diagram 2. Most of the patients referred to our department after confusion in their assessment by different consultant specialties (surgeon, internal medicine specialist and dermatologist). Comparison of the pain VAS score change after treatment among studied cases showed that the pain VAS score pretreatment between cystic and heterogeneous mass was 7.5 (6.0-9.0) and 9.0 (7.0-10.0), respectively, without a significant difference, while was $1.0(0.0-7.0)$ and 7.0 (2.0-8.0) posttreatment, respectively, with a significant statistically differences in pain relieve between cystic and heterogenous scar mass as shown in tables 2 and 3. The pain VAS score in cases with cystic lesions before and after treatment was $7.5(6.0-9.0)$ and $1.0(0.0-7.0)$, respectively, with a statistically significant difference, also VAS score in cases with heterogeneous lesions before and after treatment was $9.0(7.0-10.0)$ and $7.0(2.0-8.0)$, respectively, with a statistically significant difference with more pain relieve in response to medical treatment in cystic cases than heterogenous one as shown in table 4 . The comparison of lesion US size in $\mathrm{cm}$ before and after treatment as shown in table 5 revealed that, the mean was 2.420.67士 before treatment and $1.750 .65 \pm$ after treatment with a highly significant difference between them but without a significant difference either it was cystic or solid. The correlation between Lesion size by US, pain duration and pain VAS score showed that US lesion size had a positive correlation to pain VAS score before and after medical treatment with no relation to pain duration/ months, in addition, there was no correlation between pain VAS score before and after treatment and pain duration/months as shown in table 6 . The cut of the level of US size of cystic lesions that respond to medical treatment was $\leq 2.65 \mathrm{~cm}$ while for heterogenous lesions was $\leq 2.20 \mathrm{~cm}$ with accuracy reaching to $87.5 \%$ for cystic lesions and up to $83.3 \%$ for heterogenous lesions as shown in diagrams 3 and 4 . 


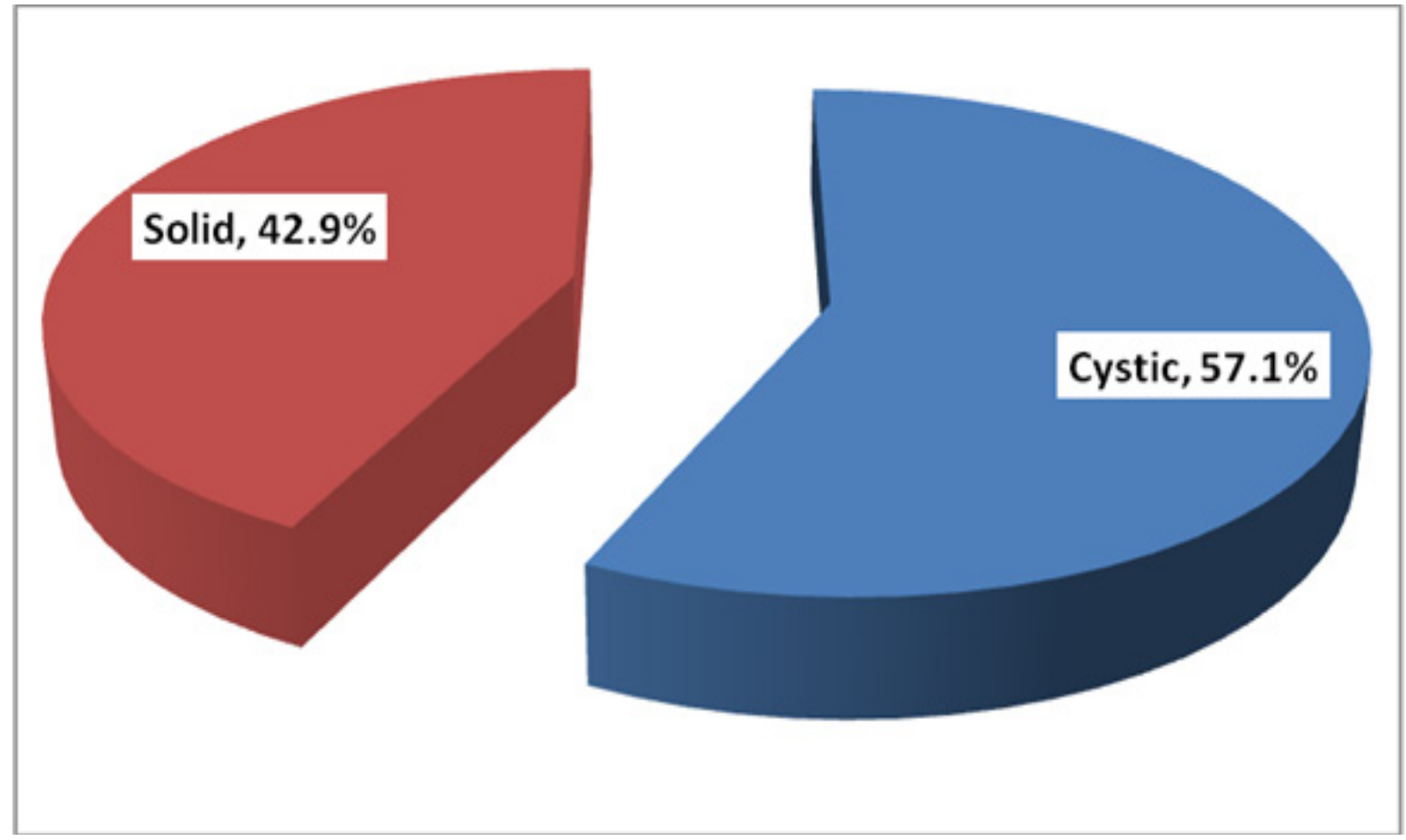

Diagram 1: It shows the consistency percentage of endometriomas masses

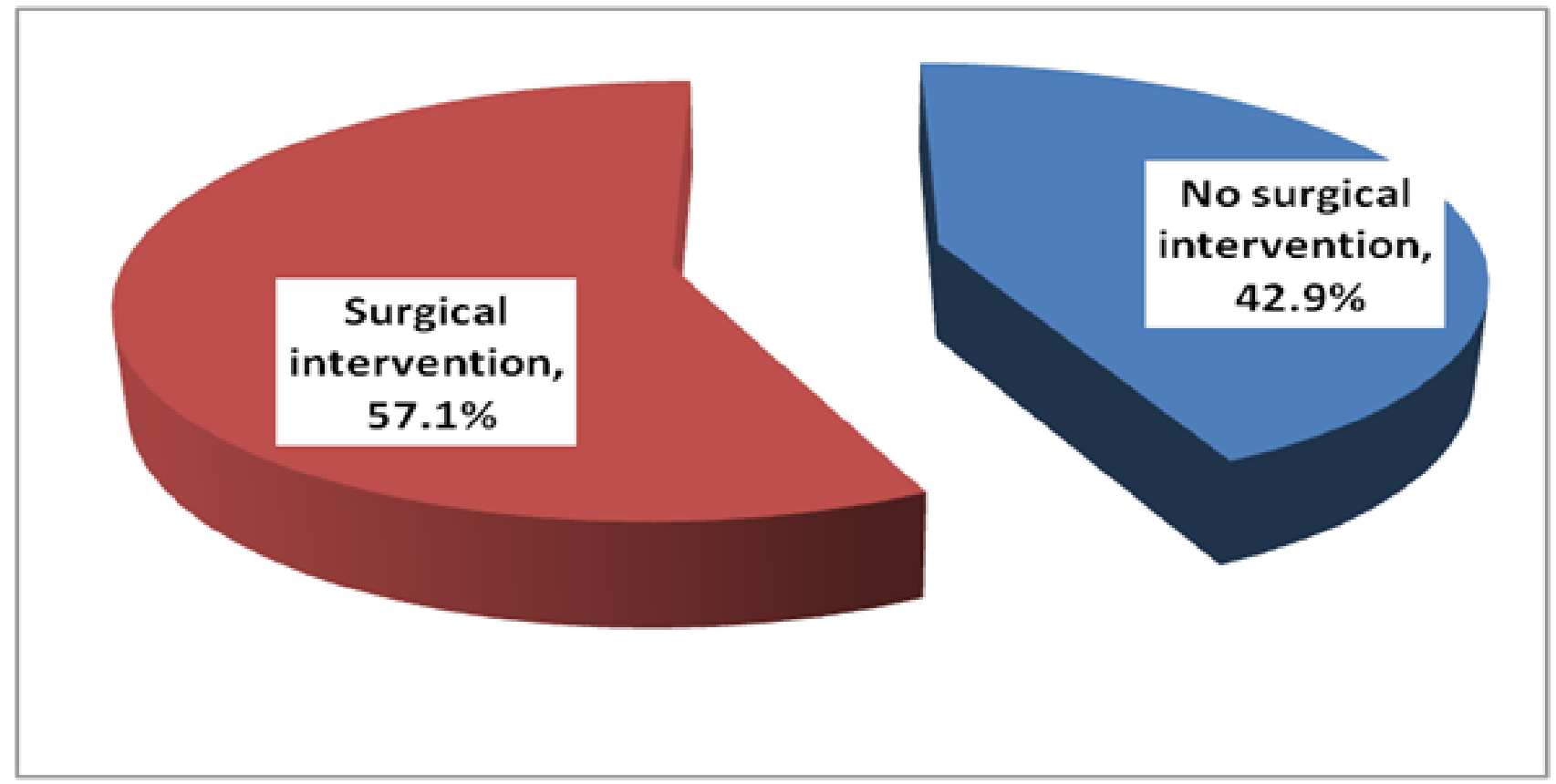

Diagram 2: It show the percentage of patients undergone surgical intervention 
Table 1: Demographic characteristics of the studied cases

\begin{tabular}{|c|c|c|}
\hline & $\mathrm{n}=14$ & $\%$ \\
\hline \multicolumn{3}{|l|}{ Age/years } \\
\hline Mean \pm SD & $28.79 \pm 4.99$ & \\
\hline (Min-Max) & $(21.0-37.0)$ & \\
\hline \multicolumn{3}{|l|}{ BMI kg/m2 } \\
\hline Mean \pm SD & $26.4 \pm 1.7$ & \\
\hline (Min-Max) & $(22.6-29.3)$ & \\
\hline Gravidity median(min-max) & $2.0(0-4.0)$ & \\
\hline 0 & 1 & 7.1 \\
\hline 1 & 3 & 21.4 \\
\hline 2 & 4 & 28.6 \\
\hline 3 & 3 & 21.4 \\
\hline 4 & 3 & 21.4 \\
\hline parity median(min-max) & $2.0(0-3)$ & \\
\hline 0 & 1 & 7.1 \\
\hline 1 & 3 & 21.4 \\
\hline 2 & 5 & 35.7 \\
\hline 3 & 5 & 35.7 \\
\hline Previous operation scar & $\mathrm{n}$ & $\%$ \\
\hline Umbilical lap port & 2 & 14.3 \\
\hline Episiotomy & 3 & 21.4 \\
\hline $\mathrm{Cs}$ & 9 & 64.3 \\
\hline $\begin{array}{l}\text { Pain VAS score before Mean } \pm \text { SD } \\
\text { (Min-Max) }\end{array}$ & $\begin{array}{l}8.0 \\
(6.0-10.0)\end{array}$ & \\
\hline $\begin{array}{l}\text { Pain VAS score after Mean } \pm \text { SD } \\
\text { (Min-Max) }\end{array}$ & $\begin{array}{l}2.0 \\
(0-8.0)\end{array}$ & \\
\hline Surgical intervention & $\mathrm{N}$ & $\%$ \\
\hline 0 & 6 & 42.9 \\
\hline 1 & 8 & 57.1 \\
\hline \multicolumn{2}{|l|}{ Pain duration/months } & \\
\hline median(min-max) & $\mathrm{n}$ & $\%$ \\
\hline Cystic & 8 & 57.1 \\
\hline Solid & 6 & 42.9 \\
\hline \multicolumn{3}{|l|}{ US size/cm before treatment } \\
\hline $\operatorname{Mean} \pm \mathrm{SD}$ & $2.42 \pm 0.67$ & \\
\hline (Min-Max) & $(1.6-4.1)$ & \\
\hline \multicolumn{3}{|l|}{ US size $/ \mathrm{cm}$ after treatment } \\
\hline Mean \pm SD & $1.75 \pm 0.65$ & \\
\hline (Min-Max) & $(0.9-3.2)$ & \\
\hline
\end{tabular}


Table (2): Comparison of VAS score change after treatment among studied cases

\begin{tabular}{|c|c|c|c|}
\hline VAS score & Before treatment & After treatment & test of significance \\
\hline $\begin{array}{l}\text { Median } \\
\text { (Min-Max) }\end{array}$ & $8.0(6.0-10.0)$ & $2.0(0-8.0)$ & $\begin{array}{l}\mathrm{Z}=3.34 \\
\mathrm{p}=0.001 *\end{array}$ \\
\hline
\end{tabular}

Z: Wilcoxon Signed rank test p: probability *Statistically significant $(p<0.05)$

Table (3): Comparison of VAS score change after treatment among studied cases

\begin{tabular}{llll}
\hline VAS score & $\begin{array}{l}\text { Solid } \\
\mathrm{n}=6\end{array}$ & $\begin{array}{l}\text { Cystic } \\
\mathrm{n}=8\end{array}$ & $\mathrm{z}=1.73$ \\
\hline $\begin{array}{l}\text { Before treatment } \\
\text { median (min-max) }\end{array}$ & & & $\mathrm{p}=0.08$ \\
$\begin{array}{l}\text { After treatment median } \\
\text { (min-max) }\end{array}$ & $9.0(7.0-10.0)$ & $7.5(6.0-9.0)$ & $\mathrm{z}=2.32$ \\
\end{tabular}

Z: Mann Whitney U test p: probability *Statistically significant $(p<0.05)$

Table (4): Comparison of VAS score change after treatment among cystic and solid lesions

\begin{tabular}{|c|c|c|c|}
\hline & \multicolumn{2}{|c|}{ VAS score } & \multirow[b]{2}{*}{ test of significance } \\
\hline & $\begin{array}{l}\text { Before treatment } \\
\text { median (min-max) }\end{array}$ & $\begin{array}{c}\text { After treatment } \\
\text { median (min-max) }\end{array}$ & \\
\hline Cystic & $7.5(6.0-9.0)$ & $1.0(0.0-7.0)$ & $\begin{array}{c}\mathrm{Z}=2.6 \\
\mathrm{p}=0.01 *\end{array}$ \\
\hline Solid & $9.0(7.0-10.0)$ & $7.0(2.0-8.0)$ & $\begin{array}{c}\mathrm{Z}=2.3 \\
\mathrm{p}=0.02^{*}\end{array}$ \\
\hline
\end{tabular}

Z: Wilcoxon Signed-rank test $\mathrm{p}$ : probability *Statistically significant $(p<0.05)$

Table (5): Comparison of lesion size before and after treatment

\begin{tabular}{|c|c|c|c|}
\hline & before treatment & after treatment & paired t-test \\
\hline \multicolumn{4}{|l|}{ US size/cm } \\
\hline Mean \pm SD & & & $\mathrm{t}=22.06$ \\
\hline (Min-Max) & $2.42 \pm 0.67$ & $1.75 \pm 0.65$ & $\mathrm{p}<0.001^{*}$ \\
\hline \multicolumn{4}{|c|}{ US size in solid lesions } \\
\hline Mean \pm SD & & & $\mathrm{t}=22.2$ \\
\hline (Min-Max) & $2.17 \pm 0.48$ & $1.48 \pm 0.47$ & $\mathrm{p}<0.001 *$ \\
\hline \multicolumn{4}{|c|}{ US size in cystic lesions } \\
\hline $\operatorname{Mean} \pm \mathrm{SD}$ & & & $\mathrm{t}=13.31$ \\
\hline (Min-Max) & $2.61 \pm 0.76$ & $1.95 \pm 0.72$ & $\mathrm{p}<0.001 *$ \\
\hline
\end{tabular}


Table 6: Correlation between Lesion size by US, pain duration and score

\begin{tabular}{|c|c|c|c|c|}
\hline & & Pain duration/months & Pain VAS score before & Pain relief VAS after \\
\hline \multirow{2}{*}{ US size $/ \mathrm{cm}$} & $\mathrm{r}$ & -.194 & $.773 * *$ & $.687 * *$ \\
\hline & $\mathrm{p}$ & .507 & .001 & .007 \\
\hline & & & \multicolumn{2}{|c|}{ pain duration/ months } \\
\hline \multirow{2}{*}{ Pain VAS score before } & & $\mathrm{R}$ & \multicolumn{2}{|c|}{-.309} \\
\hline & & $\mathrm{P}$ & \multicolumn{2}{|c|}{.283} \\
\hline \multirow{2}{*}{ Pain relief VAS after } & & $\mathrm{R}$ & \multicolumn{2}{|c|}{-.291} \\
\hline & & $\mathrm{P}$ & \multicolumn{2}{|c|}{.312} \\
\hline
\end{tabular}

r: Spearman correlation coefficient $* *$ statistically significant $(p<0.05)$

ROC Curve

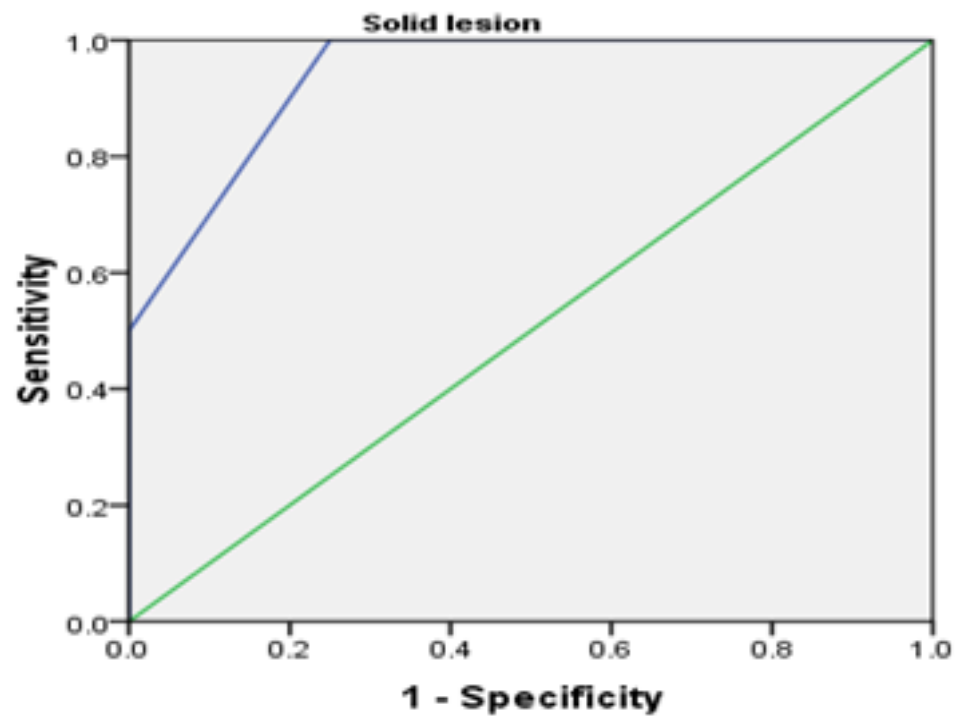

Diagonal segments are produced by ties.

Diagram 3: Show the validity of the solid lesion size in detection of pain improvement after treatment 


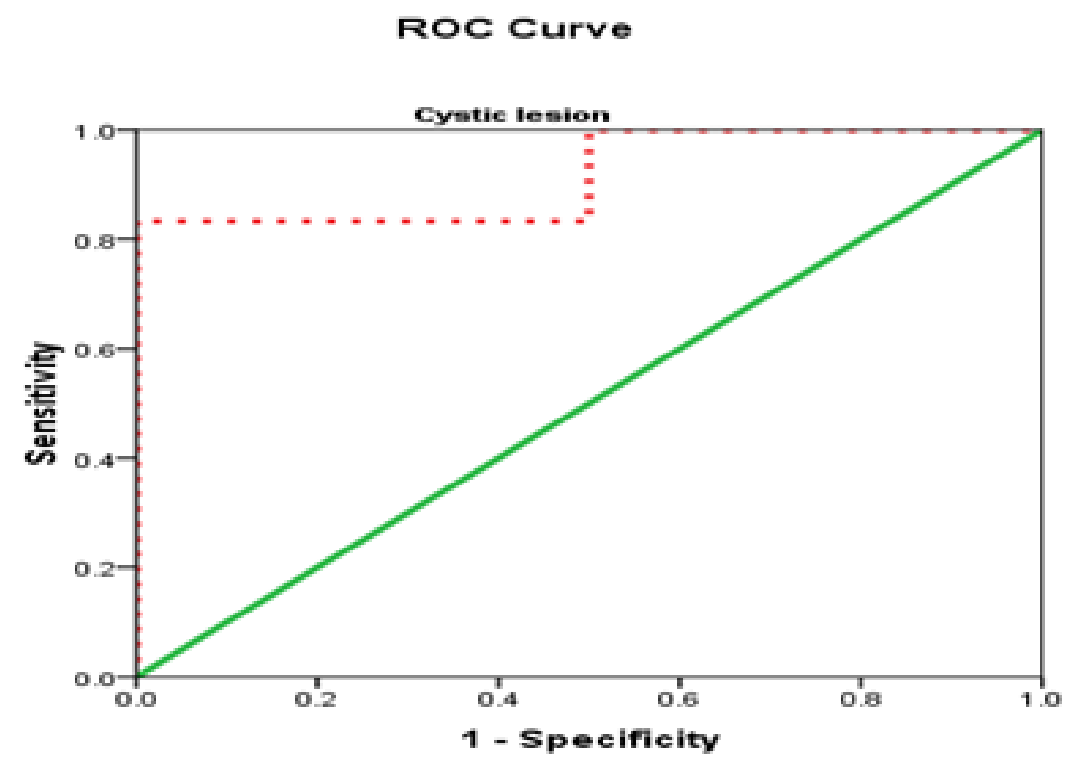

Diagram 4: Show the validity of the cystic lesion size in the detection of pain improvement after treatment

\section{DISCUSSION}

Scar endometriosis is uncommon diagnosis for gynecologist and obstetrician as it is a rare disease with confused presentation and lack of physician awareness and experience about it. Our study showed increasing in the patients presented with scar endometriosis diagnosis nowadays as there is an increase in CS frequency, in addition to increasing in laparoscopic uterine intervention which was reported by Horton et al. 2008. ${ }^{[3]}$ In our study, most of the cases presented with CS scare endometriosis then episiotomy scar as proved by the study of Medeiros FD, et al. 2011[20] which revealed that the majority of cases have been noted in and adjacent to cesarean section $(57 \%)$ or hysterectomy scars $(11 \%)$. In the lower genital tract, the most common was episiotomy scars. ${ }^{[21]}$ A study by Blanco $\mathrm{RG}$, et al. $2003^{[2]}$ has reported that scar endometriosis is the most common site after cesarean section followed by episiotomy, hysterotomy, hysterectomy and laparotomy scar. The symptoms are nonspecific, typically involving abdominal wall pain at the time of menstruation. Clinical examination and other investigations also gave non-specific results. [22] The most common presentation in our study was pain at the site of the scar with a firm lump or nodule that increased in intensity or size at time of menstruation, which was proved by Poonam Goel, et al. $2011^{[10]}$ as they stated that scar endometriosis is a rare condition and should be suspected when a lady in the reproductive age presents with pain and swelling at scar site after obstetric surgery. Cyclicity, although not always present, is pathognomic for scar endometriosis ${ }^{[23]}$. The SE diagnosis usually depends on biopsy, in this study based on data of clinical features, US and Doppler examination characteristic features for mass and FNAC characteristics findings. The US diagnostic features of SE reported by Francica et al. ${ }^{[6]}$ in their series were : a nonhomogeneous hypoechoic texture with scattered internal hyperechoic echoes, margins usually are spiculated with infiltration to the tissues surrounding and a variable width hyperechoic ring surround $\mathrm{it}^{[6]}$. The presence of a single avascular pedicle attached to the mass at the periphery with color Doppler examination ${ }^{[13]}$. FNAC is a simple and non-invasive technique which is the investigation of choice in SE cases for accurate and timely preoperative diagnosis $^{[2]}$. SE therapeutic management of choice is essentially based on wide surgical excision with safety margins at least $1 \mathrm{~cm}$ and reconstruction of damaged tissue ${ }^{[18]}$. Hormonal suppression with the use of progestogens, oral contraceptive pills and danazol is not effective and gives only partial relieve in SE symptoms. Recently, there has been a report of the use of LHRH analogue that has the prompt improvement in SE symptoms without a change in the lesion size ${ }^{[2]}$. Hormonal therapy can be initiated as a treatment for SE disorders, so we can avoid unnecessary surgery in selected cases ${ }^{[25]}$. Our study revealed that the treatment of SE with LHRH analogue for 6 months showed significant relieve of pain symptoms with more pain relieve in response to medical treatment in cystic cases than heterogenous one, in addition to significant 
decrease in lesions sizes without a significant difference either it was cystic or solid lesions that allow the ability to postpone surgical intervention and decrease surgical dissection size or need for closure with synthetic mesh, as approved by Oh EM et al. $2014^{[26]}$, as their study reported that medical treatment with hormone suppression has been suggested to relieve SE symptoms, in addition to Purvis RS and Tyring SK $1994^{[27]}$, studies which revealed that preoperative hormonal therapy can be used in SE cases with large endometriotic masses for reducing the size of the surgical defect. This study approved that the size of the US size of cystic lesions at which it responds to medical treatment was $\leq 2.65 \mathrm{~cm}$, while for heterogenous lesions was $\leq 2.20 \mathrm{~cm}$ with accuracy reaching to $87.5 \%$ for cystic lesions and up to $83.3 \%$ for heterogeneous lesions. On the other hand, F. M. González Valverde FM et al. ${ }^{[28]}$ reported that medical treatment with LHRH analogue, danazol or gestagens are ineffective in incisional endometriomas which are bigger than $2 \mathrm{~cm}$. Scar endometriosis prevention through abdominal wall wound cleaning and irrigate it vigorously with high jet saline before closure ${ }^{[29]}$.

\section{CONCLUSION}

Medical treatment with LHRH analogue is effective in pain to relieve and minimizing lesions sizes which are $2.65 \mathrm{~cm}$ or less for cystic lesions and $2.20 \mathrm{~cm}$ or less for heterogenous lesions that provide treatment options to postpone surgical intervention desire, surgical contraindication, patient refusal and decrease surgical excision size that may minimize repair with synthetic mesh.

\section{RECOMMENDATIONS:}

We need for increasing awareness of extra-pelvic endometriosis disorder and more expanded studies to study the effect of LHRH analogue treatment on the need for synthetic mesh reconstructions during surgical excision of scar endometriomas.

\section{CONFLICT OF INTEREST}

There are no conflicts of interest.

\section{REFERENCES}

1. Patterson GK, Winburn GB. Abdominal wall endometriomas: report of eight cases. Am Surg. 1999; 65:36-39.

2. Blanco RG, Parithivel VS, Shah AK, Gumbs MA, Schein M, Gerst PH: Abdominal wall endometriomas. Am J Surg 2003; 185: 596-598.
3. Horton JD, DeZee KJ, Ahnfeldt EP, Wagner M. Abdominal wall endometriosis: A surgeon's perspective and review of 445 cases. Am J Surg. 2008; 196:207-212.

4. Healy JT, Wilkinson NW, Sawyer M: Abdominal wall endometrioma in a laparoscopic trocar tract: a case report. Am Surg 1995; 61: 962-963.

5. Kocakusakna A, Arpinar E, Arikan S, Demirbag N, Tarlaci A, and Kabaca C: Abdominal Wall Endometriosis: A Diagnostic Dilemma for Surgeons: Med Princ Pract. 2005; 14:434-437.

6. Francica G, Giardiello C, Angelone G, Cristiano S, Finelli R, Tramontano G. Abdominal wall endometriosis near cesarean delivery scars. J Ultrasound Med. 2003:22:1041-7.

7. Kaloo P, Reid G, Wong F. Caesarean section scar endometriosis:Two cases of recurrent disease and a literature review. Aust NZ J Obstet Gynaecol. 2002; 42:218-20.

8. Tanos B, Anteby SO. Cesarean scar endometriosis. Int J Gynaecol Obstet. 1994; 47:163-6.

9. Douglas C, Rotimi O. Extragenital endometriosis: A clinicopathological review of Glasgow hospital with case illustrations. J Obstet Gynaecol. 2004; 24:804-8.

10. Goel P, Devi L, Tandon R, Saha PK, Dalal A. Scar endometriosis e A series of six patients: International Journal of Surgery. 2011;9: 39-40.

11. Berkley KJ, Dmitrieva N, Curtis KS, Papka RE: Innervation of ectopic endometrium in a rat model of endometriosis. Proc Natl Acad Sci USA 2004; 101: 11094-11098.

12. Sharon J. Song, Cindy M. McGrath, and Gordon H. Yu. Fine-Needle Aspiration Cytology of Endometriosis: Diagn. Cytopathol. 2017; 45:359-363.

13. Pados G, Tympanidis J, Zafrakas M, Athanatos $\mathrm{D}$, Bontis JN. Ultrasound and MR imaging in the preoperative evaluation of two rare cases of scar endometriosis. Cases J 2008; 1:97.

14. Gupta RK. Fine-needle aspiration cytodiagnosis of endometriosis in cesarean section scar and rectus sheath mass lesions e- a study of seven cases. DiagnCytopathol 2008; 36:224-6.

15. Gupta RK, Green C, Wood KP. Fine needle aspiration cytodiagnosis of endometriosis in an abdominal scar after cesarean section. Cytopathology. 2000; 11:67-8. 
16. Perez-Soane C, Vargas J, De Agustيn P. Endometriosis in an inguinal crural hernia: diagnosis by fine needle aspiration biopsy. Acta Cytol.1991; 35: 350-352.

17. Seidel AS, Sickel JZ, Warner ED, Sax HC. Extrapelvic endometriosis: diagnosis and treatment. Am J Surg. 1996; 171: 239-241.

18. Khachani I, Adib AF, and Bezad R. Cesarean Scar Endometriosis: An Uncommon Surgical Complication on the Rise? Case Report and Literature Review. Case Reports in Obstetrics and Gynecology.Volume 2017, Article ID 8062924, 4 pages.

19. Pathan SK, KapilaK, HajiBE, et al. Cytomorphological spectrum in scar endometriosis: A study of eight cases. Cytopathology 2005; 16:94-99.

20. Medeiros FD, Cavalcante DI, Medeiros MA, Eleuterio J. Fine-Needle aspiration cytology of scar endometriosis: Study of seven cases and literature review. Diagn Cytopathol. 2011; 39:18-21.

21. Isbister WH: Endometriosis in an episiotomy scar preceding pelvis endometriosis. ANZ J Surg. 2002; 72:314-315.

22. Balleyguier C, Chapron C, Chopin N, Hélénon O, Menu Y. Abdominal wall and surgical scar endometriosis: Results of magnetic resonance imaging. Gynecol Obstet Invest 2003; 55:220-2.
23. Pathan ZA, Dinesh US, Rao R. Scar Endometriosis. J Cytology. 2010; 27:106-108.

24. Patel BS, Tripathi JB, Patel FB, Rawal SA, Patel S, Gupta M. Extrapelvic Endometriosis: A Study of 17 Cases. J South Asian Feder Obst Gynae. 2012; 4(1): 32-34.

25. Griffi $n$ JB, Betsill WL Jr: Subcutaneous endometriosis diagnosed by fine needle aspiration cytology. Acta Cytol 1985; 29: 584-588.

26. Oh EM, Lee W, Kang JM, Choi ST, Kim KK, and Lee, "A surgeon's perspective of abdominal wall endometriosis at a cesarean section incision: nine cases in a single institution," Surgery Research and Practice, vol. 2014, Article ID 765372, 4 pages.

27. Purvis RS, Tyring SK. Cutaneous and subcutaneous endometriosis. Surgical and hormonal therapy. J Dermatol Surg Oncol. 1994 Oct;20(10):693-5.

28. González Valverde FM, Barberá FM, Aguado MM, Torregrosa M, Hernández Quiles A, Menárguez Pina F, Gómez Ramos MJ, García Real M, Barreras Mateos JA and Vázquez Rojas JL. Extraperitoneal endometriosis: a diagnosis to be considered. Eur Surg. 2004; 36/4: 253-256.

29. Wasfie T, Gomez E, Seon S, Zado B. Abdominal wall endometrioma after cesarean section: A preventable complication. Int Surg. 2002; 87:175-77. 